\title{
Inducible nitric oxide synthase immunoreactivity in healthy rat pancreas
}

\section{Nurullah Keklikoglu}

Istanbul University, Faculty of Dentistry, Department of Histology and Embryology, Istanbul, Turkey

\begin{abstract}
Nitric oxide (NO) is produced by NO synthase (NOS) isoforms: neuronal NOS (nNOS), endothelial NOS (eNOS) and inducible NOS (iNOS). It is believed that, while nNOS and eNOS are effective in regulation of normal physiological processes, iNOS is expressed at an increasing rate especially in inflammatory process. The aim of this study was to determine the presence of iNOS immunoreactivity (iNOS-IR) and, to compare the iNOS-IR in islet of Langerhans cells (LC), acinar cells (AC), centroacinar cells (CC) and ductal cells (DC) by immunohistochemical (IHC) method in healthy rat pancreata. This study revealed the presence of iNOS-IR in all cell types except AC. Statistical analysis revealed a highly significant difference $(\mathrm{p}<0.001)$ with respect to iNOS-IR in comparison of all cell types. However, binary comparison of cell types revealed no significant differences between LC and DC $(\mathrm{p}=0.136)$, significant differences LC and CC, CC and DC $(\mathrm{p}=0.001$ and 0.022 , respectively) and a highly significant differences $\mathrm{LC}$ and $\mathrm{AC}, \mathrm{AC}$ and $\mathrm{DC}(\mathrm{P}<0.001)$. The results of this study indicate that iNOS-IR is present in almost all LC. Thus, especially in reseach related to diabetes, it should not be disregarded that iNOS may be constitutively present in pancreatic islets.
\end{abstract}

Key words: Inducible nitric oxide synthase - iNOS - Pancreas - Islets of Langerhans - Acinar cells

\section{Introduction}

It is known that endogenous nitric oxide (NO) is affecting exocrine and endocrine pancreatic secretion in humans [1]. However, NO production in cells, exceeding the amount necessary for normal biological activities, results in cell death by apoptosis and tissue damage [2-4]. NO is produced by enzyme nitric oxide synthase (NOS), which is a short-lived mediator that can be produced in various cell types. Suppression of NOS reduces pancreatic enzyme secretion, plasma insulin and pancreatic polypeptide levels [1]. There are three major types of NOS isoforms, two of them are $\mathrm{Ca} 2+$ /calmodulin-dependent isoforms called neuronal NOS (nNOS) and endothelial NOS (eNOS). These two are also collectively called constitutive NOS (cNOS). The third one is $\mathrm{Ca} 2$ +/ calmodulin independent isoform, inducible NOS (iNOS) [5]. As it can be deduced from this common definition and labeling, while cNOS is principally involved in regulation of normal physiological activities, increasing iNOS expression

Correspondence: N. Keklikoglu, Istanbul Universitesi, Dishekimligi Fakultesi, Histoloji ve Embriyoloji BD, Capa, Istanbul, Turkey; tel.: (+90212) 4142020-30221,

e-mail: nkeklik@istanbul.edu.tr occurs during inflammatory process and some malign transformations. It is mentioned in very few articles that iNOS expression in pancreatic islet beta-cells modulates endocrine cell functions [6]. However, there is no sufficient number of research about constitutive expression of iNOS under normal physiological conditions.

It is claimed that iNOS is involved in diabetogenesis [7]. It is also believed that in insulin-dependent diabetes mellitus (IDDM), possible mediator of pancreatic beta-cell damage is radical NO and iNOS is the most involved of NOS isoforms in immune mediated beta-cell damage [8]. High level of NO produced by iNOS is related to pancreatic beta-cell disfunction and apoptosis [2,3]. IDDM is characterized by inflammatory reaction in and around Langerhans islets followed by selective destruction of insulin producing betacells. This inflammatory reaction is caused by macrophages, monocytes, $\mathrm{T}$ and $\mathrm{B}$ lymphocytes and natural killer cells [9]. These cells, being the humoral mediators of immunologic process, produce and release various cytokines. Cytokines are immunological effector molecules responsible for inhibition of insulin secretion from pancreatic beta-cells and inducting beta-cell destruction [10]. It is clear that in islets exposed to cytokines, there is a high level of iNOS 
expression, followed by overproduction of NO, however NO is necessary but not sufficient by itself in cytokine-mediated selective beta-cell destruction [11].

The source of NO production which mediates islet cell damage has been discussed, NO production in beta-cells, macrophages, ductal cells, and endothelial cells has been considered and it has been shown that NO which induces damage on beta-cells may be produced in beta-cells [12]. In another research, contribution of ductal cells in this process (because they are very close to beta-cells) has been analyzed, human ductal cells have been cultured with various cytokines, and comparison of the magnitude of iNOS mRNA expression and nitric oxide production in these cells with that in isolated human islets have shown that more than half of the total NO production might originate from associated ductal cells. Relying on this data, it has been claimed that ductal cells are a potantial source of NO production in human islets which have been infiltrated by cytokine-releasing immunocytes, and in early stages of insulitis, ductal cells in periphery of pancreatic islets might be a major target for cytokines released by immunocytes [13].

Despite the common belief that the expression of iNOS in beta-cell and following beta-cell destruction is a response of beta-cells to cytokines, constitutive presence of iNOS in pancreas and Langerhans islets and the physiological amount has not been exactly elucidated. Moreover, there is some research about iNOS expression increase/decrease caused by other factors (6). It has been observed that glucose stimulates islet activities of cNOS and iNOS dose-dependently, cNOS-derived NO inhibits glucose-stimulated insulin release strongly, and that this short-term hyperglycemia in mice induces islet iNOS activity. Hyperglycemia-evoked islet NOS activity may be one of the many factors of glucose-stimulated insulin release disorder in type II diabetes mellitus [14].

For survival of beta-cells which have been exposed to proinflammatory cytokines, focusing on iNOS expression may be useful [15]. It has been shown that pharmacological inhibition of iNOS protects against beta-cell damage both in vitro and in vivo, and reduces the sensitivity of animals deficient in iNOS against induction of diabetes [16-19]. However, it has also been shown that cytokines induce beta-cell impairment, independent of NO production [20-22]. iNOS is one of the many factors in beta-cell destruction, thus inhibition of it is not sufficient for prevention of diabetes [23]. In determining the role of iNOS in diabetogenesis, and conducting research about iNOS for diabetes prevention, it is necessary to shed some light on constitutive expression of iNOS in pancreas and the factors which can increase/decrease this expression.

The aim of this study was to determine whether the presence of iNOS immunoreactivity (iNOS-IR) and, if
Table 1. Distribution of iNOS immunoreactivity (iNOS-IR) in islet of Langerhans cells (LC), acinar cells (AC), centroacinar cells (CC) and ductal cells (DC) in healthy rat pancreata.

\begin{tabular}{|c|c|c|c|c|}
\hline \multirow{2}{*}{ Cell type } & \multicolumn{4}{|c|}{ iNOS -IR } \\
\cline { 2 - 5 } & $\begin{array}{c}- \\
\mathrm{n}(\%)\end{array}$ & $\begin{array}{c}+ \\
\mathrm{n}(\%)\end{array}$ & $\begin{array}{c}++ \\
\mathrm{n}(\%)\end{array}$ & $\begin{array}{c}+++ \\
\mathrm{n}(\%)\end{array}$ \\
\hline $\mathrm{LC}$ & 0 & 0 & 0 & $10(100)$ \\
\hline $\mathrm{AC}$ & $10(100)$ & 0 & 0 & 0 \\
\hline $\mathrm{CC}$ & 0 & $2(20)$ & $6(60)$ & $2(20)$ \\
\hline $\mathrm{DC}$ & 0 & 0 & $2(20)$ & $8(80)$ \\
\hline
\end{tabular}

so, to compare the iNOS-IR in islet of Langerhans cells (LC), acinar cells (AC), centroacinar cells (CC) and ductal cells (DC) by immunohistochemical (IHC) method in healthy rat pancreata.

\section{Materials and methods}

Animals and tissue samples. iNOS-IR in LC, AC, CC, and DC was analyzed in formalin-fixed, paraffin-embedded sections by IHC methods. Ten healthy female Wistar rats (10-12 weeks, $200 \pm$ $20 \mathrm{~g}$ ) were used. Animals had been housed in a colony room at an ambient temperature of $22 \pm 1{ }^{\circ} \mathrm{C}$, maintained under a $12: 12$ hour light-dark cycle, and fed normal diet. The rats were sacrificed under ether anesthesia and their pancreata were removed. All experiments were conducted in compliance with the guidelines of the Principles of Laboratory Animal Care (NIH publication No. 8623, revised 1985).

Samples processing and immunohistochemistry. Tissue samples were fixed in $10 \%$ buffered formalin for 18 hours. After tissues were fixed, samples were rinsed with phosphate buffered saline (PBS), and the specimens were subsequently dehydrated in ethanol, cleared in xylene and embedded in paraffin. Sections $(5-6 \mu \mathrm{m})$ were cut and mounted on glass slides. The sections were deparaffinized in xylene, rehydrated in decreasing concentrations of ethanol and covered with $10 \mathrm{mM}$ sodium citrate buffer $(\mathrm{pH}=6.0)$, heated at $95^{\circ} \mathrm{C}$ for 5 minutes, for antigen retrieval. Endogenous peroxidase activity was quenched by $5 \mathrm{~min}$. incubation in peroxidase blocking solution (DBS Universal Immunostaining Kit, CA).

Tissues were then incubated with the rabbit polyclonal antibody against iNOS (Chemicon, CA) for 2 hours and then in the biotinylated secondary antibody for 10 minutes (DBS Universal ?mmunostaining Kit, CA). Negative controls were performed by substituting the primary antibody with nonimmune rabbit serum. Immunoreactivity was detected by means of horseradish-peroxidase (HRP)streptavidin complex using diaminobenzidine (DAB) chromogen as a marker (DBS Universal Immunostaining Kit, CA). Sections were counterstained in Mayer's hematoxylin for 30 seconds. Subsequently, the sections were rinsed and finally mounted (DBS CC/Mount, CA). All steps were carried out at room temperature in a humidified chamber. Assessments, counts and photography were performed by a light microscope (Laborlux K, Leitz, Germany).

10 slides for each rat, a total of 100 slides prepared from the pancreatic tissue samples, were evaluated. Initially, positive immunostaining cells were counted in LC on the whole slide, and the percentages were calculated. Next, positive and negative AC, $\mathrm{CC}$, and DC were counted in random microscopic areas of exocrine pancreas, in the same rat with the same magnification power and with the same number of islets of Langerhans. Thus, percentages within each cell types for each rat were calculated and a single ratio was given. 

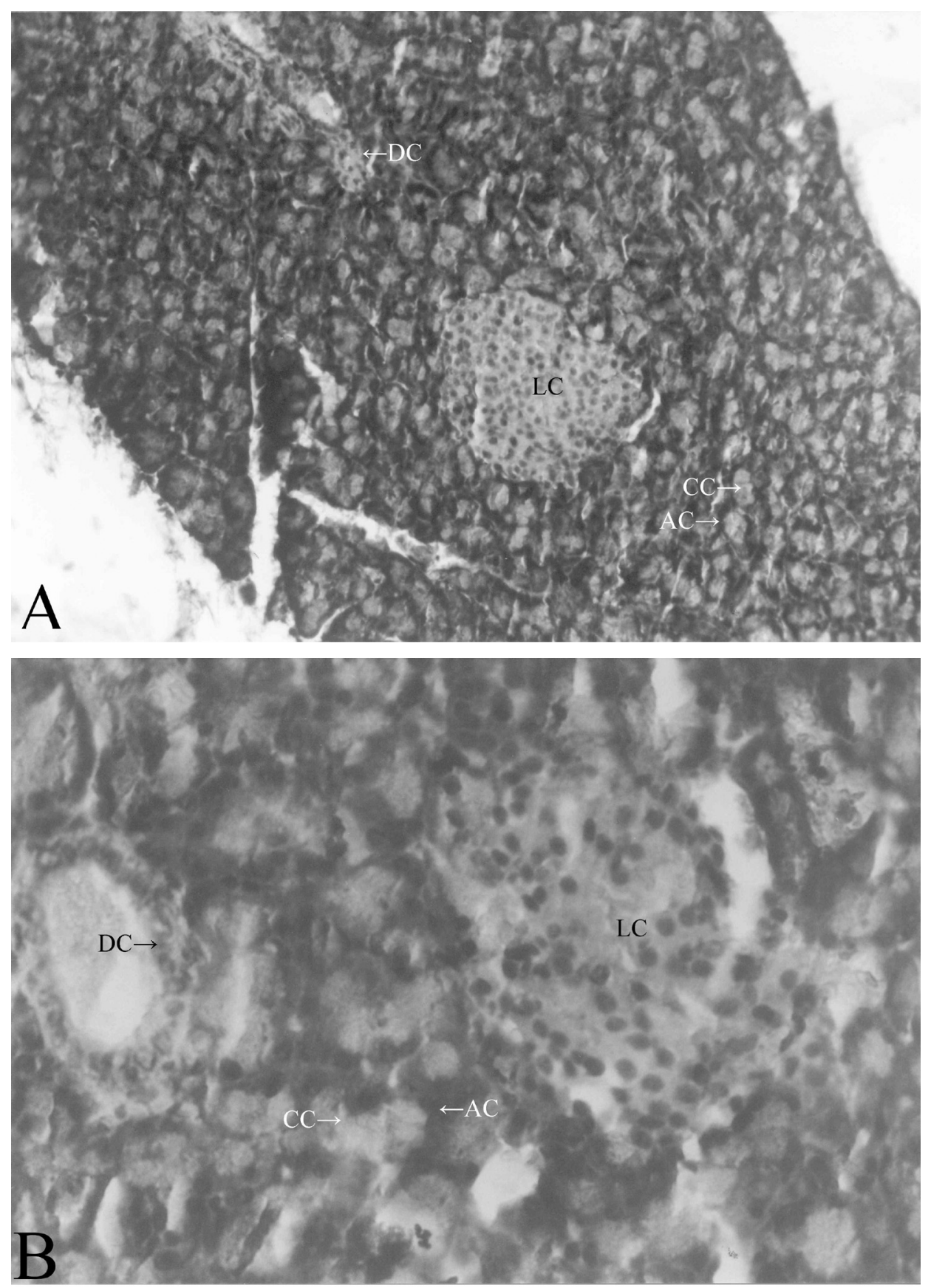

Fig. 1. Immunoreactivity for iNOS in islet of Langerhans cells (LC), acinar cells (AC), centroacinar cells $(\mathrm{CC})$ and ductal cells (DC) in pancreas of healthy rat. Different levels of iNOS -IR positivity were seen in $\mathrm{LC}, \mathrm{CC}$ and DC. No positive immunostaining was observed in AC. Counterstained with hematoxylin; original magnification $\times 160(\mathbf{A})$ and $\times 400($ B) .
The results of immunohistochemical staining were evaluated semiquantitatively on the basis of a four-point scale: - negative staining; + low expression, less than $10 \%$ of positive cells; ++ moderate expression $10-50 \%$ of positive cells; +++ diffuse expression, more than $50 \%$ of positive cells.

Statistical analysis. Statistical analysis was performed using Pearson chi-square test. $\mathrm{p}$ values $<0.05$ were considered significant.

\section{Results}

Different levels of iNOS-IR positivity were detected in 3 different cell types, namely LC, CC and DC. In all
iNOS-IR positive cells, mediocre immunoreactivity was observed. iNOS-IR was observed in almost all $\mathrm{LC}$, but surprisingly there was no immunoreactivity in $\mathrm{AC}$, or it was not intense enough to be detectable by these methods. Sections serving as negative controls were all unstained.

iNOS-IR in tissues was diffuse in $100 \%$ of LC; diffuse in $20 \%$, moderate in $60 \%$, and low in $20 \%$ of CC ; diffuse in $80 \%$ and moderate in $20 \%$ of DC, iNOS-IR was negative in $100 \%$ of AC (Fig. 1A and 1B), (Table 1).

Statistical analyses (Pearson chi-square test) revealed a highly significant difference $(p<0.001)$ with 
respect to iNOS-IR in comparison of all cell types. However, binary comparison of cell types revealed no significant differences between $\mathrm{LC}$ and $\mathrm{DC}(\mathrm{p}=0.136)$; significant differences $\mathrm{LC}$ and $\mathrm{CC}, \mathrm{CC}$ and $\mathrm{DC}$ ( $\mathrm{p}=0.001$ and 0.022 , respectively) and a highly significant differences LC and AC, AC and DC $(\mathrm{p}<0.001)$.

\section{Discussion}

In IDDM, autoimmune beta-cell destruction occurs either directly by cell-mediated cytotoxicity or indirectly by cytokines released from infiltrating lymphocytes. It is almost certain that proinflammatory cytokines induce expression of iNOS, which produces NO, resulting in beta-cells damage [23], and beta-cells have been determined as the source of this NO [24].

Although NO induced by cytokines have toxic and inhibitory effect on islets, NO produced under physiological conditions contributes to cellular functions in pancreatic beta-cells just like in other cells. It is not determined which NOS isoform produces NO under physiological conditions. Research results show that cytokine-induced apoptosis is generally NO-indepentent, but NO is necessary for necrosis [25] and cytokines can induce both NO-dependent and NOindependent inhibition of beta-cell function [26]. It is claimed that beta-cell function disorder in rat pancreatic islets following intraveneous infusion of glucose or intralipid, is at least partially madiated by induction of iNOS [27]. This data shows that iNOS expression is not solely dependent on cytokine induction but can be affected by other factors.

While there are many ongoing research which aim to illimunate the role of iNOS in diabetogenesis [7] and prove the benefits of iNOS inhibitor utilisation in treatment and prevention of diabetes [16-19], it should be considered that expression mechanism of iNOS is still not entirely elucidated. The results obtained by this research show that in almost all of LC, iNOS-IR is present in healthy pancreata.

The fact that there is no iNOS-IR in serous AC of exocrin pancreas indicates that iNOS may be expressed in cells related to cell functions. While there is no iNOS-IR in AC, it is present in CC, which may indicate that the presence of iNOS may be related to cell localizations.

Beta-cells and DC have been determined as the source of iNOS which has been expressed as a result of cytokine induction $[12,13]$. This research shows that the most of the iNOS-IR in pancreas is present in LC and DC. Further research is necessary to determine which amount of iNOS in Langerhans islets is physiological.

To conclude, it should be accepted that mainly cytokines and some other possible factors may cause overexpression of iNOS, which may result in beta-cell destruction and diabetes. Especially in reseach related to diabetes, it should not be disregarded that iNOS which is considered as the main factor in islet beta-cell destruction, is also constitutively present in pancreatic islets. The presence of iNOS in pancreas may vary with species, affected by environmental factors, and also vary with cell functions and cell localizations.

\section{References}

[ 1] Konturek JW, Hengst K, Kulesza E, Gabryelewicz A, Konturek SJ, Domschke W. Role of endogenous nitric oxide in the control of exocrine and endocrine pancreatic secretion in humans. Gut. 1997;40:86-91.

[ 2] Qader SS, Ekelund M, Andersson R, Obermuller S, Salehi A. Acute pancreatitis, expression of inducible nitric oxide synthase and defective insulin secretion. Cell Tissue Res. 2003;313:271-279.

[3] Petrik J, Arany E, McDonald TJ, Hill DJ. Apoptosis in the pancreatic islet cells of the neonatal rat is associated with a reduced expression of insulin-like growth factor II that may act as a survival factor. Endocrinology. 1998;139:2994-3004.

[4] Feng X, Yi S, Hawthorne WJ, Patel AT, Walters SN, O'Connell PJ. Inducible nitric oxide synthetase is expressed in adult but not fetal pig pancreatic islets. Xenotransplantation. 2000; 7:197-205.

[5] Knowles RG, Moncada S. Nitric oxide synthases in mammals. Biochem J. 1994;298:249-258.

[6] Eckhardt W, Bellmann K, Kolb H. Regulation of inducible nitric oxide synthase expression in beta cells by environmental factors: heavy metals. Biochem J. 1999;338:695-700.

[ 7] Pieper CM, Roza AM, Henderson JD Jr, Zhu YR, Lai CS. Spatial distribution and temporal onset of NF-kB activation and inducible nitric oxide synthase within pancreatic islets in the pre-diabetic stage of genetic, diabetic-prone BB rats: attenuation by drug intervention decreases inflammatory cell infiltration and incidence of diabetes. Inflamm Res. 2004;53: 22-30.

[ 8] Eizirik DL, Flodstrom M, Karlsen AE, Welsh N. The harmony of the spheres: inducible nitric oxide synthase and related genes in pancreatic beta cells. Diabetologia. 1996,39:875890.

[ 9] Blair LA, Maggi LB Jr, Scarim AL, Corbett JA. Role of interferon regulatory factor-1 in double-stranded RNA-induced iNOS expression by mouse islets. J Biol Chem. 2002;277: 359-365.

[10] McDaniel ML, Kwon G, Hill JR, Marshall CA, Corbett JA. Cytokines and nitric oxide in islet inflammation and diabetes. Proc Soc Exp Biol Med. 1996;211:24-32.

[11] Johannesen J, Pociot F, Karlsen AE, Mandrup-Poulsen T, Nerup J. Strain-dependent difference in inducible nitric oxide synthesis (iNOS) expression in rat pancreatic islets correlates with interferon regulating factor 1 (IRF-1) and heat shock protein 70 (HSP70) expression. Eur Cytokine Netw. 2001;12: 501-509.

[12] Thomas HE, Darwiche R, Corbett JA, Kay TW. Interleukin-1 plus gamma-interferon-induced pancreatic beta-cell dysfunction is mediated by beta-cell nitric oxide production. Diabetes. 2002;51:311-316.

[13] Pavlovic D, Chen MC, Bouwens L, Eizirik DL, Pipeleers D. Contribution of ductal cells to cytokine responses by human pancreatic islets. Diabetes. 1999;48:29-33.

[14] Henningsson R, Salehi A, Lundquist I. Role of nitric oxide synthase isoforms in glucose-stimulated insulin release. $\mathrm{Am} \mathrm{J}$ Physiol Cell Physiol. 2002;283:C296-304. 
[15] McCabe C, Samali A, O'brien T. Beta cell cytoprotective strategies: establishing the relative roles for iNOS and ROS. Biochem Biophys Res Commun. 2006;342:1240-1248.

[16] Kleemann R, Rothe H, Kolb-Bachofen V, et al. Transcription and translation of inducible nitric oxide synthase in the pancreas of prediabetic BB rats. FEBS Lett. 1993;328:9-12.

[17] Lukic ML, Stosic-Grujicic S, Ostojic N, Chan WL, Liew FY. Inhibition of nitric oxide generation affects the induction of diabetes by streptozotocin in mice. Biochem Biophys Res Commun. 1991;178:913-920.

[18] Lindsay RM, Smith W, Rossiter SP, McIntyre MA, Williams BC, Baird JD. N omega-nitro-L-arginine methyl ester reduces the incidence of IDDM in BB/E rats. Diabetes. 1995;44:365368.

[19] Flodstrom M, Tyrberg B, Eizirik DL, Sandler S. Reduced sensitivity of inducible nitric oxide synthase-deficient mice to multiple low-dose streptozotocin-induced diabetes. Diabetes. 1999;48:706-713.

[20] Eizirik DL, Sandler S, Welsh N, et al. Cytokines suppress human islet function irrespective of their effects on nitric oxide generation. J Clin Invest. 1994,93:1968-74.

[21] Flodstrom M, Morris SM Jr, Eizirik DL. Role of the citrullinenitric oxide cycle in the functional response of adult human and rodent pancreatic islets to cytokines. Cytokine. 1996;8: 642-650.

[22] Delaney CA, Pavlovic D, Hoorens A, Pipeleers DG, Eizirik DL. Cytokines induce deoxyribonucleic acid strand breaks and apoptosis in human pancreatic islet cells. Endocrinology. 1997;138:2610-2614.

[23] Kuttler B, Steveling A, Kloting N, Morgenstern O, Wanka H. Aminoguanidine downregulates expression of cytokineinduced Fas and inducible nitric oxide synthase but not cytokine-enhanced surface antigens of rat islet cells. Biochem Pharmacol. 2003;66:2437-2448.

[24] Tabatabaie T, Vasquez AM, Moore DR, Floyd RA, Kotake Y. Direct administration of interleukin-1 and interferon-gamma to rat pancreas leads to the in vivo production of nitric oxide and expression of inducible nitric oxide synthase and inducible cyclooxygenase. Pancreas. 2001;23:316-322.

[25] Liu D, Pavlovic D, Chen MC, Flodstrom M, Sandler S, Eizirik DL. Cytokines induce apoptosis in beta-cells isolated from mice lacking the inducible isoform of nitric oxide synthase (iNOS-/-). Diabetes. 2000;49:1116-1122.

[26] Andersson AK, Borjesson A, Sandgren J, Sandler S. Cytokines affect PDX-1 expression, insulin and proinsulin secretion from iNOS deficient murine islets. Mol Cell Endocrinol. 2005;240:50-57.

[27] Ekelund M, Qader SS, Jimenez-Feltstrom J, Salehi A. Selective induction of inducible nitric oxide synthase in pancreatic islet of rat after an intravenous glucose or intralipid challenge. Nutrition. 2006;22:652-660.

Submitted: 4 June, 2007 Accepted after reveiws: 11 February, 2008 